\title{
ADHD in Kindergarten Students: What Teachers Know and Experience
}

\author{
Carlin Miller*, Brianne Brooker \\ Department of Psychology, University of Windsor, Canada
}

Submission: April 25, 2017; Published: May 31, 2017

*Corresponding author: Carlin Miller, Department of Psychology, University of Windsor, Canada, Email: cjmiller@uwindsor.ca

\begin{abstract}
With the advent of full-time kindergarten, many teachers in inclusive kindergarten classrooms feel overwhelmed by the needs of their students, particularly students with ADHD. However, few studies to date have explicitly examined kindergarten teachers' experiences with ADHD, or their knowledge of the disorder. In a south western Ontario sample, kindergarten teachers ( $N=53$ ) reported that, while they implemented a number of interventions to improve the behaviors of students with ADHD, they experienced a number of barriers to intervention. The behaviors of students with ADHD and barriers to intervention challenged the coping skills of kindergarten teachers, who reported a number of symptoms of distress, including sleep problems and headaches. Results of this study support faculties of education increasing the content on exceptionalities, particularly ADHD to their pre-service teachers, and school boards devoting more resources to helping teachers better understand and cope with ADHD, especially as schools transition to universal full-time kindergarten.
\end{abstract}

Keywords: ADHD; Kindergarten; Teacher experiences

\section{Introduction}

Kindergarten teachers play a vital role in the development of young learners. They are the first educators many students experience and, as such, may form an important and lasting impression on a child's educational trajectory. They have many responsibilities, including providing academic instruction, helping students to cope with anxieties over separation from home [1], teaching socio-emotional skills [2], and managing a significant range of child behaviors [3]. These behaviors range from developmentally-appropriate fears to toileting difficulties, difficulties tolerating frustration, and aggression. For some students, particularly those who did not attend daycare or preschool, they may serve as a surrogate parent during the school day. And, they typicallysupport at least a few students experiencing significant difficulties, including disorders such as Attention-deficit/Hyperactivity Disorder (ADHD) [4].

ADHD is one of the most common childhood psychiatric disorders, with symptoms that are often present prior to school entry [5] that affects an estimated 5-7\% of children during the elementary years [6]. Kindergarten students with ADHD often exhibit significant hyperactivity and impulsivity, but may also struggle with distractibility [7]. These symptoms not only require classroom resources [3], but also often result in disciplinary and psychological assessment referrals [8,9]. Significant ADHD symptoms prior to school entry also confer greater risk for students' experience of significant comorbid difficulties, such as difficult cognitive and behavior problems, speech and language delays, socio-emotional problems, and poor pre-academic skills [10]. Thus, students with ADHD are sure to be part of inclusive kindergarten settings and, in many cases, require significant resource commitment [9].

Inclusive education has been a standard practice in school settings for more than three decades, with neurotypical children and those with a range of difficulties, disorders, and disabilities placed in the same classroom. Teachers report having a positive orientation toward inclusion models of education, yet also report they do not feel prepared to provide inclusive education well [11]. This may be because very few teacher education programs offer coursework that provides "nuts and bolts" content about developing and managing an inclusive classroom [12]. The limitation in preparation portends risk for long-term difficulties for teachers.

In addition to the limits of teacher training on inclusion broadly defined, there are multiple studies that support the assumption that teachers also do not feel well prepared to teach 
students with ADHD [13-18]. This problem is also pressing for teachers-in-training: one study suggested that $100 \%$ of undergraduate education majors surveyed thought they would benefit from additional training or coursework in ADHD [13] and few programs offer significant coursework in the area of ADHD [19]. Likewise, special education teachers also report needing more training in managing behaviors associated with ADHD in the classroom and developing appropriate accommodations for students with ADHD [20]. Some researchers have argued that this is also true amongst teachers who have been in the field for a number of years $[18,21]$, yet results from a more recent study suggest that teacher experience is inversely related to teacherreported concerns about ADHD symptoms [22]. However, all of these studies sampled teachers across multiple grades with minimal inclusion of teachers in the kindergarten years. Furthermore, this lack of training cited by multiple studies may be a significant barrier to providing adequate inclusive educational services to kindergarten students with ADHD [23].

The inclusive schoolroom has important implications for students. Despite its widespread implementation, the research on outcomes associated with inclusion has been somewhat mixed. From a positive perspective, children with exceptionalities and their neurotypical peers mutually benefit from the social contact and opportunities for affiliation [24]. There is also evidence to support the assumption that neurotypical children in inclusion settings are more likely to demonstrate enhanced tolerance for peers with special [25]. Yet, more recent research suggests that neurotypical children do not necessarily view children with disabilities as their friends at school and the effect may be particularly marked in girls [26]. The evidence for academic benefits is also equivocal; with studies suggesting that some, but not all, children with exceptionalities experience improve academic achievement outcomes following inclusive placements [27]. Yet very few studies have focused on the experiences of children with ADHD and those around them in the inclusive kindergarten classroom.

According to multiple studies, teachers have the potential to promote positive outcomes for children with ADHD, both within and outside of the inclusive classroom setting. For example, teachers are often the first person to encourage a parent to consider seeking an assessment for their child who may have ADHD [28,29]. Teachers may even offer opinions about the use of stimulant medication treatment in the ADHD treatment planning for the child $[30,31]$. Even without adequate pre-service training about ADHD, including information about treatment/ intervention for ADHD, teachers have strong convictions about treatments for ADHD [32]. Indeed, at least one study reported that some teachers may be generally skeptical about the efficacy of stimulant medications as a treatment for ADHD [20].

There is also support for the role of the teacher's preferences and opinions in the efficacy of classroom intervention overall, such that teacher preference for behavioral treatment over medication is a predictor of overall treatment outcomes for children with ADHD [33]. Furthermore, teacher knowledge and attitudes have been shown to influence treatment compliance in the child, even when the treatment involves stimulant medications [34]. Thus, the kindergarten classroom teacher is an important partner with parents and others in developing and implementing an appropriate treatment plan for a young student with ADHD. Despite the empirical evidence and anecdotal reports suggesting that teachers are not receiving enough training in ADHD and do not feel well-prepared to support students with ADHD in the classroom, there remains overwhelming evidence that teachers are important individuals in the process of a child being diagnosed with ADHD and receiving appropriate intervention.

Adding to the importance of responsibilities and roles of teachers, our Canadian province (Ontario) has recently moved to full-time (five days per week each with a full school day for two years) kindergarten for all children who are four years old by the end of a given calendar year. This means that in an academic year, there may be children as young as three at the beginning of the year in a kindergarten classroom and as old as six years old at the end of the year. With research suggesting that up to half of children with ADHD symptoms at diagnostic levels in preschool will no longer meet diagnostic criteria by grade one [35], many children who will "outgrow" their ADHD symptoms over the course of their kindergarten experience will exhibit significant difficulties with self-control, high activity level, and impairing distractibility as they start kindergarten.

In this study, our aim was to survey kindergarten teachers about their knowledge of ADHD, as well as their experiences with students who have ADHD and the emotional effects of those experiences for these teachers in a local school board. We focused our attention on kindergarten teachers as these are the first teachers many students encounter in the K-12 education system and there is scant data to document their experiences with and knowledge about children with ADHD. We hypothesized that the challenges inherent to ADHD symptoms in young learners would have a significant impact of teachers. The research for the project received clearance from the ethics board where the research team was located and all participants provided informed consent prior to participation.

\section{Methods}

\section{Participants}

Participants were in-service kindergarten teachers in a large school board in south-western Ontario who participated in the survey. Consistent with the school board's policy at that time, teachers were recruited through their school principals. All principals of schools with kindergarten programs $(\mathrm{N}=38)$ were contacted by phone and 31 principals agreed to approach their teachers about participating. In total, 88 teachers were given the opportunity to participate (i.e., they received survey materials), 
of which 53 teachers returned completed surveys by mail. This sample represents $50 \%$ of all kindergarten teachers employed in the school district.

All of the participants were female and were largely of Caucasian descent (96.2\%). Of those surveyed, $72 \%$ had completed a bachelor's degree, $14 \%$ had completed at least some graduate training, and 14\% held an Early Childhood Educator certificate but not a university degree. Overall, participating teachers were highly experienced, with a mean of 15.75 years teaching ( $\mathrm{SD}=7.51$; range: 1 - 34 years).

\section{Materials}

Teacher survey. Initial questions were demographic queries, including current teaching assignment, gender, race/ ethnicity, years of experience teaching, and highest level of education. Because there are no validated measures to address teacher experiences and coping with ADHD, we developed questions based on a review of the relevant literature on the types of interventions that are most effective for children with ADHD, the types of barriers that teachers encounter in making modifications/accommodations for ADHD in inclusive classrooms, and somatic symptoms of stress. We included queries about the participant's strategies for coping with ADHD in the classroom and the severity of problems associated with ADHD. We asked the teacher to endorse which interventions a teacher had used in the past three years for a student with ADHD or suspected to have ADHD, as well as the barriers to implementing interventions. We also asked the teacher about their psychological experiences of working with students who have ADHD (i.e., experiencing worry or stress, needing to "vent" more often, as well as physical symptoms of psychological distress such as headaches, etc.). The internal consistencies (Chronbach's $\alpha$ ) for the four sections of this brief measure were 0.59 ("Coping with ADHD in the classroom"), 0.61 ("Interventions"), 0.60 ("Barriers to Intervention"), and 0.74 ("Your experiences working with children with ADHD"). All of these questions are included in Appendix A.

\section{Appendix: Teacher Survey Items}

\section{Coping With ADHD in the Classroom:}

If you are struggling with a child whom you suspect to have ADHD, what strategies do you use? (Circle all that apply):
a. Nothing
b. Wait to see if the child outgrows it
c. Talk to the child's parent
d. Ask the parent to take their child to his/her physician
e. Seek consultation from a peer
f. Seek consultation from your LSST
g. Seek consultation from a specialist outside your building

\section{h. Other (please specify).}

Does your school system have adequate resources available to support JK/SK classroom teacher who work with children who have ADHD?

YES

$$
\text { NO }
$$

I DON'T KNOW

Do children with ADHD represent a significant problem for JK/ SK teachers?

$$
\text { YES }
$$

I DON'T KNOW

\section{Interventions:}

There are a number of interventions that might be used with children who have or who are suspected to have ADHD. In the table, please check the boxes of the interventions that you implemented or have been aware of a child in your class

\begin{tabular}{|c|c|}
\hline & YES \\
\hline \multicolumn{2}{|l|}{ Modified the classroom environment } \\
\hline \multicolumn{2}{|l|}{ Modified classroom routines } \\
\hline \multicolumn{2}{|l|}{ Modified the child's assignments } \\
\hline \multicolumn{2}{|l|}{ Modified expectations or rules for the child } \\
\hline \multicolumn{2}{|l|}{ Increased home-school communication } \\
\hline \multicolumn{2}{|l|}{ Consultation with the LSST (Spec Ed teacher) } \\
\hline \multicolumn{2}{|l|}{ Services from the LSST } \\
\hline \multicolumn{2}{|l|}{ Assessment with a school psychologist } \\
\hline \multicolumn{2}{|l|}{ Assessment with an outside psychologist } \\
\hline \multicolumn{2}{|l|}{ Involvement with a paraprofessional/aide } \\
\hline \multicolumn{2}{|l|}{ Medication } \\
\hline \multicolumn{2}{|l|}{ Tutoring } \\
\hline \multicolumn{2}{|l|}{ Counselling (at school) } \\
\hline \multicolumn{2}{|l|}{ Counselling (outside school) } \\
\hline \multicolumn{2}{|l|}{ Social skills group } \\
\hline \multicolumn{2}{|l|}{ No intervention provided to a child } \\
\hline \multicolumn{2}{|l|}{ No children with ADHD in class } \\
\hline Other (please specify below) & \\
\hline
\end{tabular}
experiencing in the last three years.

\section{Barriers to Intervention:}

There are many reasons a child does not receive intervention in the classroom. What reasons apply to your student's or students' situation in the last three years?

\begin{tabular}{|c|}
\hline Lack of time \\
\hline Large class size \\
\hline Too many students with special needs \\
\hline Lack of peer support \\
\hline Lack of administrative support \\
\hline Interventions recommended are ineffective \\
\hline Lack of materials/resources \\
\hline Lack of training \\
\hline
\end{tabular}




\begin{tabular}{|c|}
\hline Lack of communication with parents \\
\hline Lack of cooperation from parents \\
\hline Lack of communication with physician \\
\hline Discomfort with ADHD interventions \\
\hline Too many other demands \\
\hline Child with ADHD was uncooperative \\
\hline
\end{tabular}

\section{Your Experiences Working with Children with ADHD:}

Teachers report different experiences when working with a student with ADHD. Please describe your experiences in the last three years.

When I think about teaching a child with ADHD, I feel worried or stressed.

$$
\text { YES }
$$$$
\text { SOMETIMES }
$$

When I am interacting with a child with ADHD, I feel frustrated by his/her behaviour.

\section{YES SOMETIMES}

When I have a child with ADHD in my class, I find myself "venting" more often with colleagues or friends.

YES

SOMETIMES

NO

Having a child with ADHD in my classroom increases the likelihood I will experience:

\begin{tabular}{|c|c|c|c|}
\hline Fatigue or feeling tired & YES & SOMETIMES & NO \\
\hline Bodily pains & YES & SOMETIMES & NO \\
\hline Headaches & YES & SOMETIMES & NO \\
\hline Need for more "down-time" & YES & SOMETIMES & NO \\
\hline Feeling worried or upset & YES & SOMETIMES & NO \\
\hline Difficulty sleeping & YES & SOMETIMES & NO \\
\hline Feeling overwhelmed & YES & SOMETIMES & NO \\
\hline Feeling distracted & YES & SOMETIMES & NO \\
\hline Irritability with others & YES & SOMETIMES & NO \\
\hline
\end{tabular}

Attention Deficit-Hyperactivity Disorder Knowledge and Opinion Survey (AKOS). The AKOS is a three-part survey about ADHD. The first section is a 14-item true/false-format "quiz" about ADHD based on the empirical literature. The second section is a 12 -item opinion survey that asks participants to endorse items, such as "I believe medication helps children with ADHD," on a 1 (strongly disagree) to 6 (strongly agree) scale. The last section surveys about how participants acquire information about ADHD (i.e., watching television programs, reading newspaper stories, etc.). This measure has been shown to have strong reliability and validity in several previous studies using Canadian samples.

\section{Procedure}

All of the study questions were completed in paper-andpencil format and returned by mail. All participants received a
$\$ 10$ gift card to thank them for their participation. They were also given the opportunity to be entered in a random draw for a $\$ 50$ gift certificate to a local shopping mall. All statistical analyses were completed using SPSS 22.0.

\section{Results}

Teacher experiences with ADHD. In the survey of teachers' experiences with students with ADHD, all of the participants identified at least one strategy for coping with ADHD in the classroom and $37.7 \%$ described ADHD as a significant problem for JK/SK teachers. The most commonly endorsed strategies for addressing students' ADHD were talking to the child's parent (96.2\%), seeking consultation from the special education teacher $(88.7 \%)$, seeking support and consultation from peers (54.7\%), and asking the parent to take the child to the family physician (54.7\%). Teachers reported trying, on average, 7.53 different classroom interventions ( $S D=2.90$; range: 1 -15) over the last three years when working with a student with ADHD, including modifying how they communicate with the student, consulting with the special education teacher, and modifying the classroom environment for the student, including routines and expectations. The most common barriers to intervention were large class sizes and a lack of parental cooperation. A full list of the barriers to teacher intervention is summarized in Table 1.

Table 1: Barriers to Intervention Endorsed by Teachers.

\begin{tabular}{|c|c|}
\hline Barrier & \% endorsed \\
\hline Large class size & 58.5 \\
\hline Lack of parental cooperation & 56.6 \\
\hline Lack of time & 45.3 \\
\hline Too many other demands & 34.0 \\
\hline Lack of materials & 34.0 \\
\hline Recommended interventions are ineffective & 34.0 \\
\hline Lack of training & 32.1 \\
\hline Too many children with special needs & 30.2 \\
\hline
\end{tabular}

Table 2: Distress Symptoms Endorsed by Teachers.

\begin{tabular}{|c|c|}
\hline & \% endorsing \\
\hline Bodily pains & 86.7 \\
\hline Difficulty sleeping & 79.2 \\
\hline Need for more "down time" & 69.8 \\
\hline Headaches & 67.9 \\
\hline Fatigue or feeling tired & 62.3 \\
\hline Feeling distracted & 60.4 \\
\hline Feeling overwhelmed & 58.5 \\
\hline Irritability with others & 56.6 \\
\hline Feeling worried or upset & 50.9 \\
\hline
\end{tabular}

Teachers endorsed a considerable number of symptoms they believe are associated with their work with students who have ADHD. For example, 24.5\% feel worried or stressed, $16.9 \%$ are frustrated by ADHD-related issues, and $47.2 \%$ need to "vent" more often with colleagues. In terms of somatic complaints, 
teachers reported, on average, 5.11 symptoms $(\mathrm{SD}=2.38$, Range: 0-9) that they attributed to their work with students with ADHD in the last year. The most common items endorsed were bodily pains and sleep difficulties. A summary of the symptoms endorsed appears in Table 2.

Teacher knowledge of ADHD. On the AKOS, teachers correctly answered, on average 9.13 questions out of 14 correctly (65.2\%; range: $6-13)$. In the opinions section of the measure, $58.5 \%$ of teachers surveyed would be reluctant to give their own child medication if their child was diagnosed with ADHD and $66.1 \%$ of teachers were uneasy about medication due to media coverage. In contrast, $96.2 \%$ endorsed medication as an effective treatment for ADHD and $90.6 \%$ felt medications are safe. All of the participants endorsed family counseling as beneficial for learning skills to cope with a child with ADHD. Finally, $83.0 \%$ of participants thought that parents do not use effective discipline strategies for the child with ADHD. When surveyed about where they gain information about ADHD, teachers cited peers as their most frequent source of information (90.6\%). Parents of students with ADHD (79.2\%) and books (73.6\%) were other common sources.

Based on the results of the planned analyses, we conducted additional post-hoc analyses in order to address demographic Table 3: Descriptive Statistics and Results of Final Post-hoc Statistical Analysis.

\begin{tabular}{|c|c|c|c|c|c|}
\hline & $\begin{array}{c}\text { Group endorsing } \\
\text { ADHD is not a } \\
\text { significant problem } \\
\text { Mean (SD) } \\
\text { Range }\end{array}$ & $\begin{array}{c}\text { Group endorsing the } \\
\text { ADHD is a significant } \\
\text { problem } \\
\text { Mean (SD) } \\
\text { Range }\end{array}$ & $\begin{array}{c}\text { F } \\
\text { df (1, 47) }\end{array}$ & p \\
\hline $\begin{array}{c}\text { Total interventions } \\
\text { tried }\end{array}$ & $\begin{array}{c}.17(2.61) \\
3-14\end{array}$ & $\begin{array}{c}6.00(2.41) \\
0-11\end{array}$ & 8.75 & .005 & .16 \\
\hline $\begin{array}{c}\text { Total barriers to } \\
\text { intervention reported }\end{array}$ & $\begin{array}{c}5.14(2.76) \\
0-10\end{array}$ & $\begin{array}{c}2.95(2.06) \\
0-7\end{array}$ & 9.05 & .004 & .16 \\
\hline
\end{tabular}

\section{Discussion}

In this study, kindergarten teachers were surveyed about their knowledge, opinions, and experiences in their work with students who have ADHD. Our emphasis on kindergarten teachers was intended to bring light to an area where little research has previously been conducted. Although teachers were concerned they did not receive adequate training for working effectively with students who have ADHD, they reported using a number of interventions to help these students. They also reported a number of barriers to intervention, representing classroom challenges, lack of support from parents and administration, and systemic challenges. Notably, those teachers who were trying more interventions were also less likely to describe ADHD as being a significant problem and to report fewer barriers to intervention. The teachers also reported significant personal difficulties resulting from the challenges they were facing in the classroom.

Results of this study suggest that although ADHD is a common problem in the kindergarten years, teachers clearly do factors that may have played a role in the results. Using a median split, we divided the participants into two groups: those who were less experienced teachers (mean years of experience $=9.58$ years, $\mathrm{SD}=4.43$; range $=1-14)$ and those who were more experienced teachers $($ mean $=21.04$ years, $\mathrm{SD}=5.20$; range 15-21). There were no statistically significant differences in knowledge about ADHD, number of interventions tried, number of barriers experienced, total stress experienced, or overall coping between the two groups ( $p>$.20). The groups were also divided in terms of level of education (those with and without graduate training) and perceived adequacy of resources to support students with ADHD. No differences between groups were noted ( $p>.20)$. As a final post-hoc analysis, we divided the participants into two groups based on whether they thought ADHD was a significant problem in the kindergarten years. (The three participants who endorsed "I don't know" for this question were not included in this final analysis, nor were the two participants with missing data.) These groups were highly similar in terms of knowledge about ADHD and stress experienced ( $p>.20$ ), but those who did not view ADHD as a problem in kindergarten classrooms reported trying significantly more interventions and reported significantly fewer barriers to intervention. A summary of the descriptive statistics and statistical analyses from the final posthoc tests appears in Table 3. not always feel well-equipped to manage the potentially complex educational and behavioral needs of children with ADHD. Of specific concern is the limited knowledge these teachers have about ADHD. Although we used a psychometrically valid quiz for teachers about ADHD that was brief and therefore may have inadequately sampled the teachers' breadth of knowledge about ADHD, the limits in their knowledge are in line with their requests for more training. Although the mean level of knowledge held by the teachers was similar to those in the normative sample [36], they nonetheless reflect that our participating teachers tended to possess several misconceptions about the disorder and its implications. Furthermore, our teacher participants reported that they were not comfortable with their current knowledge; the vast majority of our participants indicated they want more training and skills for working with this population of learners who are more active, less attentive, and more impulsive than neurotypical kindergarten students.

These gaps in knowledge may contribute to participants' significant reluctance toward stimulant treatment (medication) 
for ADHD. The vast majority of the participants acknowledged the medications to be both safe and effective but many would be reluctant to consider medication for their own child if they were to be diagnosed with ADHD. The media, particularly social media, has been highly critical of the use of stimulant medications [37], but there is empirical evidence to support the safe and efficacious use of medication in the treatment of ADHD, even in young children. Although there are numerous psychosocial (i.e., non-medication) treatments available, all are time-intensive, require significant resources on the part of parents and teachers, and access to treatment providers, such as psychologists and behavior therapists [38]. Medication remains a highly cost-effective and relatively easily-instituted treatment for this prevalent disorder [39].

The hesitancy on the part of teachers regarding stimulant medication use is a critical issue, as teacher opinions may also play a role in parent decision-making about ADHD and child compliance with treatment [20,32,33]. Thus, future initiatives targeting increasing teachers' knowledge of research on stimulant treatments may increase parents' likelihood of initiating or continuing this important source of treatment for children with ADHD. Likewise, teachers may benefit from an enhanced understanding of the nature of psychosocial interventions, whether in the classroom or at home. Our results are consistent with several decades of research on the impact of ADHD in schools and on teachers $[13-15,17,18]$ Laurence Jerome et al., 1994). Although much of the extant work has examined these issues relevant to somewhat older students, it is clear from this study and others $[36,40]$ that the symptoms associated with ADHD influence the classroom environment--even when there is a greater emphasis on exploratory learning and comparatively less emphasis on cognitive tasks that require sitting still and individual work products, as is the case in local kindergarten classrooms. These youngest learners in schools may bring with them significant behavioral challenges, which have the potential to increase teacher-reported distress, particularly if children have ADHD.

The teachers' reports of physical and psychological health symptoms attributable to teaching students with ADHD is particularly concerning. It is clear that ADHD diagnoses are increasing in North Americav [41]; thus, it is unlikely teachers will experience relief in the form of a reduction in the incidence of ADHD symptoms in the classroom. ADHD symptoms in students may serve as an extended stressor for teachers, and may lead to teachers missing school [42]. Not only are teacher sick days expensive for school systems, the inconsistency in personnel is disruptive for students' learning and behavior [43]. Furthermore, as more teachers leave the profession prematurely due to stress and burn-out [44], the schools are losing their "institutional memory" for effective interventions for particular classrooms and schools. Thus, teachers may benefit from enhanced support and in-service training opportunities for developing and implementing effective interventions for ADHD. This may be particularly critical when schools have large class sizes and/or large numbers of parents who have limited time or who are uncooperative with school-based interventions for ADHD. Although there are significant financial challenges being faced by school systems, it may be a reasonable investment to provide this extra support if it results in a more effective and experienced teacher workforce.

Additionally, most of participating teachers in our study felt that parent discipline is generally inadequate for children with ADHD. There is empirical evidence to partially support this assumption [45], but it also potentially puts teachers in an adversarial role with parents, rather than teachers partnering with parents to improve child behavior at school and at home. Furthermore, for many parents of children with ADHD, the task of parenting is far more challenging than in neurotypical children [38]. Even those parents who participate in parenting training programs and who have excellent behavior management skills may have children who challenge their ability to parent. By placing the onus on parent decisions and parent behavior, this assumption may underestimate the child effects of this neurobiological disorder that is typically present very early in development. Although the parents' behaviors may influence the course of ADHD [46], parenting behaviors clearly do not cause this disorder or its disruptive functional outcomes.

It should be noted that there was no way for us to confirm that each teacher participant was accurately identifying students in their classrooms in the recent past who were diagnosed with ADHD. Thus, it may be that when the teachers were describing the interventions they implemented and the barriers they encountered, as well their somatic symptoms of stress during those times, they were actually describing children with more general behavior problems or children with different disorders and special needs. To reduce this effect whenever possible, teachers were repeatedly cued to ADHD as a disorder and kindergarten students with ADHD. We wanted to tap teachers' perceptions of the disorder as a whole-perceptions which shape how teachers respond to future students with ADHD and how such students may therefore perform [47]. Thus, we assert that our findings have critical implications for the success and wellbeing of both teachers and their students with ADHD.

\section{Limitations}

As is true with all studies, our work is not without limitations. This project represents a survey of a fairly small, albeit representative, local sample of kindergarten teachers. In a more urban or heavily populated school district, results may be somewhat different. Likewise, if we had expanded beyond kindergarten, we may have also found significantly different results, although it does not appear likely based on the overlap in findings with other studies. Additionally, we did not have the opportunity to directly interview participants. Thus, we were not able to tease out more of the fine details in the data relations 
or conduct qualitative analyses. All of these issues should be considered in future studies.

\section{Implications}

Our work suggests that teachers, particularly in the kindergarten years as a child is beginning their formal schooling, need more support for working with young learners who have ADHD. Although they hold positive attitudes toward working with students with ADHD, they also report significant knowledge gaps and barriers impeding their efforts to employ evidence-based intervention. Nonetheless, our study highlights that teachers are providing multiple interventions for children with ADHD and seeking additional support from their building administrators and their school boards. Faculties and schools of education may wish to consider these issues as they continue to refine their training programs. Likewise, school systems may wish to consider how in-service training may bolster the skills of teachers who are already in classrooms with students who have ADHD. Topics might include effective home-school partnerships, designing effective classroom-based interventions, and modifying classroom environments for students with ADHD. Based on teacher concerns about parents' skills, school systems may also wish to consider providing parent training programs in some cases. Schools may also wish to consider how they support teachers' self-care during times of stress and how the school promotes resiliency for all. Regardless of what changes are made, it is clear that the current system for coping with ADHD in kindergarten classrooms is not optimal for students with ADHD and their teachers.

\section{Acknowledgement}

We wish to thank the teachers who volunteered their time to participate in this study and the reviewers who provided their helpful comments in a previous version of this manuscript. Partial funding for this project was provided by the University of Windsor Humanities and Social Science Research Grant through the Office of Research and Innovation Services.

\section{References}

1. Battaglia M, Touchette É, Garon-Carrier G, Dionne G, Côté SM, et al. (2016). Distinct trajectories of separation anxiety in the preschool years: persistence at school entry and early-life associated factors. J Child Psychol Psychiatry 57(1): 39-46.

2. Denham SA, Bassett HH, Mincic M, Kalb S, Way E, et al. (2012) Socialemotional learning profiles of preschoolers' early school success: A person-centered approach. Learn Individ Differ 22(2): 178-189.

3. Saez L, Folsom JS, Al Otaiba S, Schatschneider C (2012) Relations Among Student Attention Behaviors, Teacher Practices, and Beginning Word Reading Skill J Learn Disabil 45(5): 418-432.

4. Hutchinson N, Minnes P, Burbidge J, Dods J, Pyle A, et al. (2015) Perspectives of Canadian teacher candidates on inclusion of children with developmental disabilities: A mixed-methods study. Exceptionality Education International 25(2): 42.

5. Schmiedeler S, Schneider W (2014) Attention-deficit hyperactivity disorder (ADHD) in the early years: Diagnostic issues and educational relevance. Clin Child Psychol Psychiatry 19(3): 460-475.
6. American Psychiatric Association (2014) Diagnostic and statistical manual of mental disorders. Diagnostic and Statistical Manual of Mental Disorders ( $5^{\text {th }}$ edn.). American Psychiatric Association Publishing, Washington, USA.

7. O'Neill S, Schneiderman RL, Rajendran K, Marks DJ, Halperin JM (2014) Reliable Ratings or Reading Tea Leaves: Can Parent, Teacher, and Clinician Behavioral Ratings of Preschoolers Predict ADHD at Age Six? J Abnorm Child Psychol 42(4): 623-634.

8. Demaray MK, Schaefer K, Delong LK (2003) Attention-Deficit/ Hyperactivity Disorder (ADHD): A National Survey of Training and Current Assessment Practices in the Schools. Psychology in the Schools 40(6): 583-597.

9. Marks DJ, Mlodnicka A, Bernstein M, Chacko A, Rose S, et al. (2009) Profiles of service utilization and the resultant economic impact in preschoolers with attention deficit/hyperactivity disorder. J Pediatr Psychol 34(6): 681-689.

10. Montes G, Lotyczewski BS, Halterman JS, Hightower AD (2012) School readiness among children with behavior problems at entrance into kindergarten: results from a US national study. Eur J Pediatr 171(3): 541-548.

11. Loreman T, Earle C (2007) The development of attitudes, sentiments and concerns about inclusive education in a content-infused Canadian teacher preparation program. Exceptionality Education Canada 17(12): 85-106.

12. Allday RA, Neilsen-Gatti S, Hudson TM (2013) Preparation for Inclusion in Teacher Education Pre-Service Curricula. Teacher Education and Special Education: The Journal of the Teacher Education Division of the Council for Exceptional Children 36(4): 298-311.

13. Bekle B (2004) Knowledge and attitudes about Attention-Deficit Hyperactivity Disorder (ADHD): A comparison between practicing teachers and undergraduate education students. J Atten Disord 7(3): 151-161.

14. Bussing R, Gary FA, Leon CE, Wilson Garvan C, Reid R (2002) General classroom teachers' information and perceptions of attention deficit hyperactivity disorder. Behavioral Disorder 27(4): 327-339.

15. Hepperlen TM, Clay DL, Henly GA, Barké CR (2002) Measuring teacher attitudes and expectations toward students with ADHD: Development of the Test of Knowledge About ADHD (KADD). J Atten Disord 5(3): 133-142.

16. Morgan PL, Li H, Cook M, Farkas G, Hillemeier MM, et al. (2015) Which Kindergarten Children Are at Greatest Risk for Attention-Deficit/ Hyperactivity and Conduct Disorder Symptomatology as Adolescents? Sch Psychol Q 31(1): 58-75.

17. Ohan JL, Visser TA, Strain MC, Allen L (2011) Teachers' and education students' perceptions of and reactions to children with and without the diagnostic label “ADHD”. J Sch Psychol 49(1): 81-105.

18. Weyandt LL, Fulton KM, Schepman SB, Verdi GR, Wilson KG (2009) Assessment of teacher and school psychologist knowledge of Attention-Deficit/Hyperactivity Disorder. Psychology in the Schools 46(10): 951-961.

19. Piccolo-Torsky J, Waishwell L (1998) Teachers' Knowledge and Attitudes Regarding Attention Deficit Disorder. ERS Spectrum 16(1): 36-40.

20. Snider VE, Busch T, Arrowood L (2003) Teacher Knowledge of Stimulant Medication and ADHD. Remedial and Special Education 24(1): 46-56.

21. Jerome L, Gordon M, Hustler P (1994) A comparison of American and Canadian teachers' knowledge and attitudes towards Attention Deficit Hyperactivity Disorder (AHHD). Can J Psychiatry 39(9): 563-567. 
22. DuPaul GJ, Reid R, Anastopoulos AD, Power TJ (2014) Assessing ADHD symptomatic behaviors and functional impairment in school settings: Impact of student and teacher characteristics. Sch Psychol Q 29(4): 409-421.

23. Reid R, Vasa SF, Maag JW, Wright G (1994) An analysis of teachers' perceptions of attention deficit-hyperactivity disorder. Journal of Research and Development in Education 27: 195-202.

24. Simpson RL (2004) Inclusion of Students with Behavior Disorders in General Education Settings: Research and Measurement Issues. Behavioral Disorders 30(1): 19-31.

25. Salend SJ, Garrick Duhaney LM (1999) The Impact of Inclusion on Students With and Without Disabilities and Their Educators. Remedial and Special Education 20(2): 114-126.

26. de Boer A, Pijl SJ, Post W, Minnaert A (2012) Peer Acceptance and Friendships of Students with Disabilities in General Education: The Role of Child, Peer, and Classroom Variables. Social Development 22(4): 831-844.

27. Zigmond N, Jenkins J, Fuchs D, Deno S, Fuchs LS (1995) When Students Fail to Achieve Satisfactorily: A Reply to McLeskey and Waldron. Phi Delta Kappan 77(4): 303.

28. Fabiano GA, Pelham WE, Majumdar A, Evans SW, Manos MJ, et al. (2013) Elementary and Middle School Teacher Perceptions of AttentionDeficit/Hyperactivity Disorder Prevalence. Child \& Youth Care Forum 42(2): 87-99.

29. Sciutto MJ, Terjesen MD, Frank AS (2000) Teachers' knowledge and misperceptions of Attention-Deficit/hyperactivity disorder. Psychology in the Schools 37(2): 115-122.

30. Groenewald C, Emond A, Sayal K (2009) Recognition and referral of girls with Attention Deficit Hyperactivity Disorder: case vignette study. Child Care Health Dev 35(6): 767-772.

31. Kasten EF, Coury DL, Heron TE (1992) Educators' knowledge and attitudes regarding stimulants in the treatment of attention deficit hyperactivity disorder. J Dev Behav Pediatr 13(3): 215-219.

32. Akram G, Thomson AH, Boyter AC, McLarty M (2009) ADHD and the role of medication: knowledge and perceptions of qualified and student teachers. European Journal of Special Needs Education 24(4): 423-436.

33. Power TJ, Hess LE, Bennett DS (1995) The Acceptability of Interventions for Attention-Deficit Hyperactivity Disorder Among Elementary and Middle School Teachers. J Dev Behav Pediatr 16(4): 238-243.

34. Jerome L (1995) Teacher and Parent Influences on Medication Compliance. Journal of Child and Adolescent Psychopharmacology 5(1): 85-86.

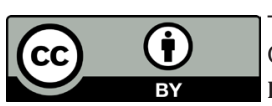

This work is licensed under Creative

Commons Attribution 4.0 License

DOI:10.19080/PBSIJ.2017.04.555634
35. Curchack-Lichtin JT, Chacko A, Halperin JM (2014) Changes in ADHD symptom endorsement: preschool to school age. J Abnorm Child Psychol 42(6): 993-1004.

36. Blotnicky-Gallant P, Martin C, McGonnell M, Corkum P (2015) Nova Scotia Teachers' ADHD Knowledge, Beliefs, and Classroom Management Practices. Canadian Journal of School Psychology 30(1): 3-21.

37. Clarke JN (2011) Magazine portrayal of attention deficit/hyperactivity disorder (ADD/ADHD): A post-modern epidemic in a post-trust society. Health, Risk \& Society 13(7-8): 621-636.

38. Hinshaw SP, Arnold LE (2015) Attention-deficit hyperactivity disorder, multimodal treatment, and longitudinal outcome: evidence, paradox, and challenge. Wiley Interdiscip Rev Cogn Sci 6(1): 39-52.

39. Fredriksen M, Dahl AA, Martinsen EW, Klungsoyr O, Faraone SV, et al. (2014) Childhood and persistent ADHD symptoms associated with educational failure and long-term occupational disability in adult ADHD. Atten Defic Hyperact Disord 6(2): 87-99.

40. Sherman J, Rasmussen C, Baydala L (2008) The impact of teacher factors on achievement and behavioural outcomes of children with Attention Deficit/Hyperactivity Disorder (ADHD): a review of the literature. Educational Research 50(4): 347-360.

41. Getahun D, Jacobsen SJ, Fassett MJ, Chen W, Demissie K, et al. (2013) Recent trends in childhood attention-deficit/hyperactivity disorder. JAMA Pediatr 167(3): 282-288.

42. Visser SN, Danielson ML, Bitsko RH, Holbrook JR, Kogan MD, et al. (2014) Trends in the parent-report of health care provider-diagnosed and medicated attention-deficit/hyperactivity disorder: United States, 2003-2011. J Am Acad Child Adolesc Psychiatry 53(1): 34-46.e2.

43. Miller RT, Murnane RJ, Willett JB (2008) Do Teacher Absences Impact Student Achievement? Longitudinal Evidence From One Urban School District. Educational Evaluation and Policy Analysis 30(2): 181-200.

44. Carlson BC, Thompson JA (1995) Job burnout and job leaving in public school teachers: Implications for stress management. International Journal of Stress Management 21(1): 15-29.

45. Heath CL, Curtis DF, Fan W, McPherson R (2015) The association between parenting stress, parenting self-efficacy, and the clinical significance of child ADHD symptom change following behavior therapy. Child Psychiatry Hum Dev 46(1): 118-129.

46. Chacko A, Wymbs BT, Flammer-Rivera LM, Pelham WE, Walker KS, et al. (2008) A pilot study of the feasibility and efficacy of the Strategies to Enhance Positive Parenting (STEPP) program for single mothers of children with ADHD. Journal of Attention Disorders 12(3): 270-80.

47. Brophy J, Good T (1987) Looking in classrooms ( $4^{\text {th }}$ edn.). Harper \& Row, New York, USA.

Your next submission with Juniper Publishers will reach you the below assets

- Quality Editorial service

- Swift Peer Review

- Reprints availability

- E-prints Service

- Manuscript Podcast for convenient understanding

- Global attainment for your research

- Manuscript accessibility in different formats

( Pdf, E-pub, Full Text, Audio)

- Unceasing customer service

Track the below URL for one-step submission

https://juniperpublishers.com/online-submission.php 